\title{
Fluidized bed gasification of biomass- In bed investigation of gas and tar formation
}

\author{
M. Mayerhofer ${ }^{\mathrm{a}, *}$, S. Fendt ${ }^{\mathrm{a}}$, H. Spliethoff ${ }^{\mathrm{a}, \mathrm{b}}$, M. Gaderer $^{\mathrm{a}}$ \\ ${ }^{a}$ Institute of Energy Systems, Faculty of Mechanical Engineering, Technische Universitaet Muenchen, Boltzmannstrasse 15, 85748 Garching, Germany

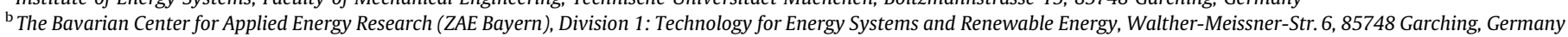

\section{H I G H L I G H T S}

- Axial tar and gas profiles are measured in fluidized bed and freeboard.

- Most tar compounds are released at the beginning of the freeboard.

- Inside the fluidized bed heterocyclic tar compounds are hardly measured.

\section{A R T I C L E I N F O}

\section{Article history:}

Received 22 November 2012

Received in revised form 1 May 2013

Accepted 21 June 2013

Available online 4 July 2013

\section{Keywords:}

Allothermal gasification

Axial profile

Tar

Fluidized bed

Biomass

\begin{abstract}
A B S T R A C T
Allothermal steam gasification in fluidized bed reactors is a promising way to convert biomass into a high quality product gas. Due to its low nitrogen content the gas can be used in a variety of processes. Besides the direct production of heat and power in, e.g. internal combustion engines (ICE), the product gas can be converted to clean synthesis gas and second generation biofuels. A major problem in all downstream applications is the high tar content in the product gas. The tar, a mixture of mostly aromatic hydrocarbons, has to be removed prior to downstream processes to avoid blocking of equipment by condensed material. Besides the operational parameters, the gas quality depends on the reactor design.

This study investigates the axial formation of tar and main gas components in an allothermal steamblown bubbling fluidized bed gasifier. Therefore an axial movable sampling probe is used to withdraw gas samples at different heights directly from within the fluidized bed as well as from the freeboard.

The gasification agent $\mathrm{H}_{2} \mathrm{O}$ decreases rapidly over the bed height. The reason is the release of volatile compounds from the injected biomass and formation of dry gas components inside the bed. The main dry gas components $\mathrm{CH}_{4}, \mathrm{CO}, \mathrm{CO}_{2}$ and $\mathrm{H}_{2}$ increase continuously over the bed height and reach a maximum at the bed surface.

The tar concentration of product gas withdrawn from inside the bed is comparably low. No oxygen containing species but only light aromatic and light polyaromatic compounds are measurable in this region. The main fraction of tar is released in the transition zone between fluidized bed and freeboard due to partially degassed fuel particles that float on the surface.
\end{abstract}

(c) 2013 Elsevier Ltd. All rights reserved.

\section{Introduction}

Environmental problems and the growing shortage of fossil fuels make it necessary to use alternative energy sources. Wind and solar power currently have the highest growth rate in Europe but have the disadvantage of being intermittent [1]. In contrast to these fluctuating sources, biomass can deliver power on demand. Furthermore, the production of hydrogen, synthetic natural gas (SNG), liquid biofuels or basic chemicals like dimethyl ether is possible using biomass [2,3]. For the latter utilization paths, the

\footnotetext{
* Corresponding author. Tel.: +49 (0)89 289 16280; fax: +49 (0)89 28916271.

E-mail address: mayerhofer@es.mw.tum.de (M. Mayerhofer).

URL: http://www.es.mw.tum.de (M. Mayerhofer).
}

gasification of biomass is the first process step and the production of a nitrogen free product gas is beneficial. To produce such a high quality product gas, allothermal steam gasification in fluidized beds seems to be a promising way $[4,5]$.

One of the major problems in product gas utilization is the production of condensable hydrocarbons, known as tar, during gasification. A detailed description of tar formation during gasification has been made by Milne and Evans and can be found in [6]. Milne and Evans describe the following evolution of tar: When biomass is heated up to pyrolysis conditions, primary tar compounds like levoglucosan, glycolaldehyde and furfural are formed as fragments of the biomass compounds cellulose hemicellulose and lignin. These compounds break up at further temperature increase and form the secondary compounds phenolics and olefins. Both, 
primary and secondary tar compounds contain oxygen and are therefore reactive and relatively easy to destroy. A further increase in temperature leads to the formation of tertiary tar compounds, aromatic ring systems that are formed out of the fragments of primary and secondary tar compounds. These tertiary products are very stable and can have a very high dew point.

Tar is a problem whenever the gas temperature cools below the tar dew point, since fouling and blocking of equipment will occur [7]. Therefore prior to further gas use (e.g. in an internal combustion engine ICE), the tar content has to be reduced drastically by primary or secondary measures [8]. At this time no fluidized bed gasifier can directly reach the limits for use in an ICE. Secondary gas cleaning and conditioning steps are indispensable and can be facilitated by a low initial tar content.

A first step in improving fluidized bed systems is to understand what happens in the reactors. Most investigations on fluidized bed gasification report about experimental data measured downstream of the gasification reactor and conclusions on the events inside the reactor are difficult. Nevertheless, some experimental facilities are equipped with several sampling points distributed along the axis of the gasification reactor. The main studies on this topic were carried out by the following researchers.

Padban and Bramer [9] use an air-blown bubbling fluidized bed reactor with a fuel input of $1 \mathrm{~kg} / \mathrm{h}$. They measure the tar composition at two heights in the freeboard after a residence time of $0.5 \mathrm{~s}$ and $1.3 \mathrm{~s}$. The tar measurement is performed using the solid phase adsorption (SPA) method [10] and the tar species are sorted into the five class system proposed by the Energy research center of the Netherlands (ECN) [9]. The authors monitor a decreasing content of class 2 components with increasing residence time in the freeboard and an increasing content of class 3 components. Since the fuel is introduced on one side of the bed in their facility, the gas profile is not axisymmetric and different effects interfere. The results for class 4 and class 5 components cannot be interpreted.

Kiel and Van Paasen $[9,11]$ use an air-blown bubbling fluidized bed gasifier with a fuel input of $1 \mathrm{~kg} / \mathrm{h}$. They measure the tar composition by SPA after different residence times in the freeboard $(1.2-5.4 \mathrm{~s})$. With increasing residence time in the freeboard, the class 2 components are reduced significantly and the class 3 components decrease moderately. The polyaromatic compounds of class 4 and class 5 tar components are increasing with increasing residence time. The number of unknown tar species is reduced significantly with increasing residence time in the freeboard.

Ross et al. [12] use a steam/air-blown bubbling fluidized bed gasifier with a fuel input of $20 \mathrm{~kg} / \mathrm{h}$. Their facility allows product gas to be sampled from the freeboard and also directly from the fluidized bed. The authors do not measure tar directly but use the concentration of gaseous $C_{2}$ and $C_{3}$ components as a tar indicator. These components increase inside the fluidized bed and have a maximum in the freeboard.

The motivation of this study is to investigate the processes inside the fluidized bed of an allothermal steam blown gasifier. The focus is on the axial tar- and gas profile and the location of the release of the tar species.

\section{Materials and methods}

\subsection{Experimental facility and measurement equipment}

The experimental facility used in this work is described elsewhere in detail [13]. Fig. 1 shows a simplified flow sheet. The gasifier is an allothermal bubbling fluidized bed reactor that uses steam as a gasification medium. The steam flow is controlled by a control valve and a coriolis mass flow meter type Rheonik (RMH 04 GET 2). The gasifier is heated electrically and the heat

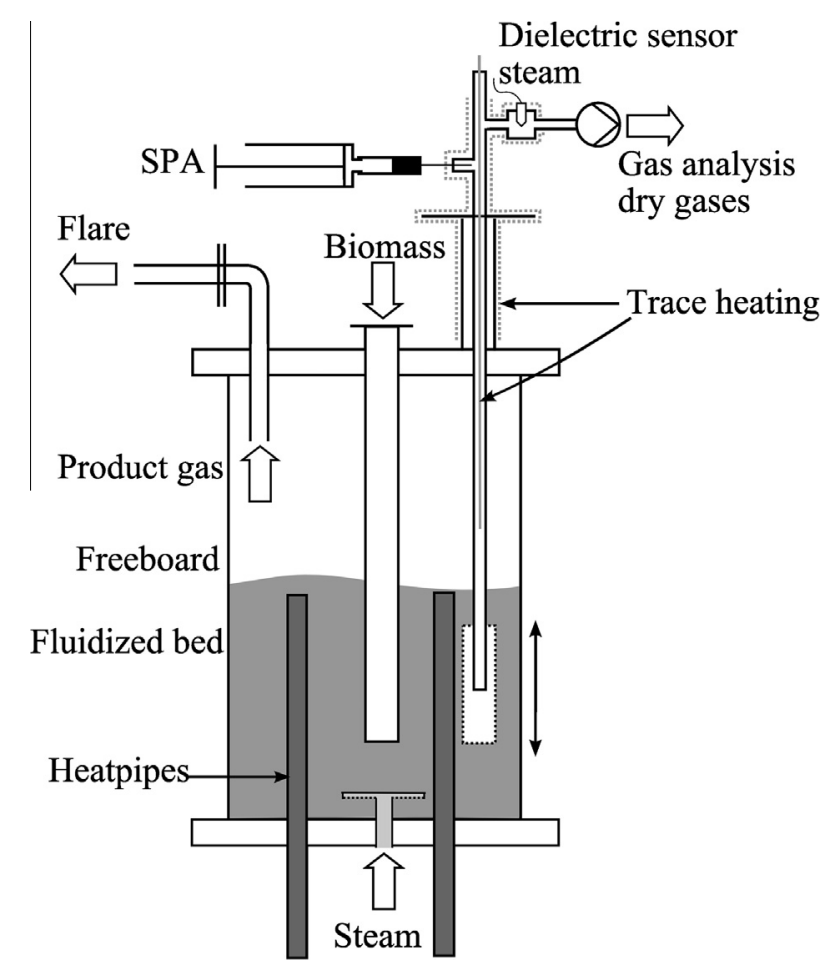

Fig. 1. Simplified flow sheet of reactor with sampling probe.

is transported via four high temperature heat pipes, which use sodium as a working fluid, into the fluidized bed. The axial temperature profile is measured with 15 thermocouples equally spaced along the axis inside the reactor vessel. The dimensions of the reactor are $154 \mathrm{~mm}$ of internal diameter and a length of $1500 \mathrm{~mm}$. The heat pipes have a diameter of $20 \mathrm{~mm}$ and a length of $660 \mathrm{~mm}$ inside the fluidized bed. The biomass particles enter the reactor via a drop tube that ends $200 \mathrm{~mm}$ above the bottom. A screw conveyor is used to transport the biomass particles into the drop tube. The drop tube is flushed with a small amount of nitrogen $(120 \mathrm{Nl} / \mathrm{h})$ to prevent product gas from entering the fuel feeding system.

The flow dynamics are influenced by the heat pipes and the drop tube to some extent and lead to the formation of a slug flow (see [14]). Under slug flow conditions the rising velocity of a bubble is influenced by the walls. Slug flows occur often in nonindustrial-scale bubbling fluidized bed facilities due to the relatively small diameters and this fact has to be taken into account for scale up.

The product gas exits the reactor and is cleaned in a cyclone and a ceramic candle filter. The main fraction of the product gas is burnt in a flare. A sampling probe is used to withdraw product gas directly from the gasifier for analysis of main gas components and the tar composition. This sampling probe consists of a sinter metal filter and a high temperature resistant stainless steel tube with an internal diameter of $4 \mathrm{~mm}$. The sampling probe is connected to the gas measurement equipment and the product gas is removed using a diaphragm pump. Any axial position can be reached within the gasification reactor to remove gas, while the sampling probe is sealed and hold in position by a gland seal.

The main dry gas components $\mathrm{CH}_{4}, \mathrm{CO}, \mathrm{CO}_{2}$ and $\mathrm{H}_{2}$ are analyzed with an IR gas analyzer (type S700, Sick Maihak). The total $\mathrm{H}_{2} \mathrm{O}$ content is measured in the slip stream of the sampling probe using a dielectric sensor (type EE31-D, E+E Elektronik). A psychrometer for steam measurement (type Hygrophil-H, Bartec) is installed in the main gas line after the gasifier. The comparison between the steam value at the highest location in the freeboard and the steam 
value in the main gas line is used to define a steam measurement error. The wet gas composition is calculated with the dry gas composition and the total $\mathrm{H}_{2} \mathrm{O}$ content

$y_{i, w e t}=y_{i, d r y} \cdot\left(1-y_{\mathrm{H}_{2} \mathrm{O}}\right)$

where $y_{i, d r y}$ is the volume concentration of a dry gas species and $y_{\mathrm{H}_{2} \mathrm{O}}$ is the total volume concentration of $\mathrm{H}_{2} \mathrm{O}$ in the product gas. The error of the wet gas composition has been estimated and includes the error of the measurement devices and the propagation of uncertainty through the calculation.

Tar analysis is carried out by taking SPA samples from an access point installed in the sampling probe. The sampling probe is heated above $350{ }^{\circ} \mathrm{C}$ until this sampling point to avoid tar condensation. Due to the pump, the gas inside the sampling probe has an absolute pressure of 800 mbar for the lowest measured axial position of $200 \mathrm{~mm}$ and $900 \mathrm{mbar}$ for the higher axial positions. This complicates the SPA sampling since it has to be ensured that no air is entering the system. For this reason no septum was used but a swagelok fitting with a clamping ring of polytetrafluoroethylene (PTFE). The pressure inside the sampling probe is monitored at the sampling point to correct the analyzed product gas volume that is drawn over the SPA sample.

\subsection{Measurement procedure}

Table 1 contains the operational parameters during the experiments. The gasifier is heated up to the final temperature of $800^{\circ} \mathrm{C}$ and fluidized with steam. The temperature is constant in the fluidized bed section, fluctuations are as low as $5 \mathrm{~K}$. No temperature drop at the point of steam injection is monitored, hence it can be assumed that the steam temperature is $800^{\circ} \mathrm{C}$ as well. The operational parameters are kept constant throughout the whole duration of each measurement series. After starting the gasification the gasifier is operated for $2-3.5 \mathrm{~h}$ before beginning with the measurements to ensure a stationary state. This is necessary since in the beginning of operation char accumulates in the reactor and influences the gas and tar composition during start up. The sampling probe is positioned at the requested height and product gas is removed with the pump. The values of the main gas components are monitored online. After reaching a stable gas composition the sampling probe stays in this position for $15 \mathrm{~min}$. After this time, two tar samples are taken using the SPA method [10]. Therefore $100 \mathrm{ml}$ of product gas are drawn with a syringe over an amino phase column. Finally the sampling probe is positioned to the next height.

Three assumptions are made concerning the processes inside the reactor and the sampling probe.

1. The sampling probe does not disturb the flow behavior inside the fluidized bed reactor. The assumption is justified since only $\approx 1 / 25$ of the product gas flow is withdrawn in the sampling probe. The possibility of overrepresenting the bubble phase in the withdrawn gas is discussed in Section 2.5 and is addressed in Section 3.

Table 1

Operational parameters.

\begin{tabular}{ll}
\hline$\dot{m}_{\text {bm }}(\mathrm{kg} / \mathrm{h})$ & 1.6 \\
$\dot{m}_{\text {steam }}(\mathrm{kg} / \mathrm{h})$ & 2.0 \\
T fluidized bed $\left({ }^{\circ} \mathrm{C}\right)$ & 800 \\
p gasifier $(\mathrm{MPa})$ & 0.1 \\
$\rho$ bed material $\left(\mathrm{kg} / \mathrm{m}^{3}\right)$ & 2650 \\
$\bar{d}$ bed material $(\mathrm{mm})$ & 0.25 \\
$u_{s}(\mathrm{~m} / \mathrm{s})$ & 0.175 \\
Fluid. $\mathrm{nr} .\left(\mathrm{v}_{\text {gas }} / \mathrm{v}_{m f}\right)$ & 5.8 \\
Bed height $(\mathrm{mm})$ & $400-500$ and $800-900$ \\
\hline
\end{tabular}

2. The time averaged gas composition is uniform in radial direction. The assumption is justified because of the good mixing in a bubbling fluidized bed.

3. The chemical reactions inside the sampling probe are negligible in comparison to reactions in the reactor. The assumption is justified since the residence time is shorter by a factor of $\approx 20$ inside the sampling probe. The residence time in the hot section of the sampling probe is in the range of 0.02-0.05 s.

Two series of measurements are presented in this study with different heights of bed material. For the first series of measurements the bed height was in the range of $400-500 \mathrm{~mm}$, the second measurements were performed at a bed height of $800-900 \mathrm{~mm}$.

\subsection{Tar measurement}

The tar was measured with the SPA method that is a commonly applied method to analyze tar compounds larger than benzene [15] up to coronene [10]. In the sampling procedure, product gas is drawn over an amino phase where the tar compounds are adsorbed. The tar components are eluded from the amino phase with dichloromethane and analyzed in a gas chromatograph. The samples are analyzed in-house using gas chromatography and a flame ionization detector (GC-FID). Therefore an Agilent GC (7890A) and an autosampler (G4513A) are used. The column is an HP-5 (30 m, $320 \mu \mathrm{m}, 0.25 \mu \mathrm{m}$ ) as stationary phase $\mathrm{H}_{2}$ is used. The GC-FID is calibrated for the most relevant 14 tar compounds. Unknown components that are present in the samples are included in the total tar sum. The unknowns are sorted into one of the five tar classes proposed by ECN [9] according to their retention time. The class 1 tars cannot be detected with GC, class 2 represents the oxygen containing heterocyclic compounds which are water soluble and class 3 to class 5 represent aromatics with increasing ring number.

For the calculation of the tar concentration in $\mathrm{g} / \mathrm{m}^{3}$ at standard temperature and pressure (STP) it is assumed that the steam contained in the product gas is condensed in the amino phase and does not enter the syringe in vapor form. With this assumption the volume refers to dry product gas.

A high amount of steam in the product gas influences the adsorption behavior of the amino phase. The amino phase is placed on a support of silicagel that is highly hygroscopic. The steam reduces the surface that is available for the adsorption of tar compounds. This leads to higher errors for the tar measurement in very wet product gases and has to be taken into account.

An error was estimated for the values presented in this work and is indicated in the graphs. This includes uncertainties of the sampling procedures as well as statistical uncertainties of the analysis. If no error bar is shown for a measurement point only one sample could be analyzed and the measurement error cannot be estimated.

\subsection{Biomass and bed material}

Wood pellets with $8 \mathrm{~mm}$ diameter and a length of 15-25 mm are used as biomass feedstock (provided by the company Lantmannen, Sweden). Proximate and ultimate analysis (Vario Macro CHNS analyzer) are given in Table 2. The pellets are commercially available under the trading name Agrol and are a blend of $80 \%$ spruce and $20 \%$ pine.

Silica sand $\left(\mathrm{SiO}_{2}\right)$ is used as a bed material. The average particle size is $0.25 \mathrm{~mm}$, the particle density is $2650 \mathrm{~kg} / \mathrm{m}^{3}$. The bulk density of the fluidized bed during operation is between $1050 \mathrm{~kg} / \mathrm{m}^{3}$ and $1500 \mathrm{~kg} / \mathrm{m}^{3}$. The fluidization number (see Table 1 ) is calculated with the approach presented in [14]. The superficial velocity in the reactor $u_{s}$ is estimated with the steam mass flow $\dot{m}_{s t}$, the steam density $\rho_{s t}$ and the free cross section of the fluidized bed $A_{f}$ by 
Table 2

Main characteristics of feedstock.

\begin{tabular}{lcl}
\hline Water content & 4.84 & wt.\% \\
Ash & 0.12 & wt.\% db \\
Volatiles & 85.58 & wt.\% db \\
Fixed C & 14.30 & wt.\% db \\
Low heating value & 20.6 & $\mathrm{MJ} / \mathrm{kg} \mathrm{db}$ \\
$\mathrm{C}$ & 49.84 & wt.\% db \\
$\mathrm{H}$ & 6.74 & wt.\% db \\
$\mathrm{N}$ & 0.10 & wt.\% db \\
$\mathrm{S}$ & 0.08 & wt.\% db \\
$\mathrm{O}$ & 43.12 & wt.\% $\left(100-\sum\right)$ \\
\hline
\end{tabular}

$\mathrm{db}=$ dry base.

Table 3

Elemental mass balance.

\begin{tabular}{llll}
\hline Element & $\mathrm{C}$ & $\mathrm{H}$ & $\mathrm{O}$ \\
\hline Input & 0.767 & 0.337 & 2.543 \\
Output bed $400-500 \mathrm{~mm}$ & 0.772 & 0.299 & 2.416 \\
Output bed $800-900 \mathrm{~mm}$ & 0.778 & 0.294 & 2.409 \\
\hline
\end{tabular}

$u_{s}=\dot{m}_{s t} /\left(\rho_{s t} \cdot A_{f}\right)$.

The value of 5.8 ensures proper fluidization and mixing of biomass particles and bed material.

\subsection{Gas sampling from fluidized beds}

Following the two phase theory, bubbling fluidized beds consist of the particle containing suspension or dense phase and the particle free bubble phase [16]. To describe the gas composition correctly, the time mean concentration based on flow through both phases needs to be measured [17]. With a sampling probe one phase (e.g. the bubble phase) can easily be overrepresented in the extracted gas flow. This can lead to erroneous interpretation of the measured data if the concentration in bubble and dense phase differ greatly. In the case of the experimental facility used, the gas compositions will differ in the bottom part of the bed: The bubbles initially contain only the fluidizing agent steam and in the dense phase the fresh fuel particles are devolatilized. Along the bed height, mass transport between both phases leads to mixing of the two gas flows. At the top of the bed the bubbles break up and both gas streams are mixed in the freeboard. To what extent the two gas flows are already mixed in the bed itself cannot be predicted but has to be concluded from the measured data. Hence great care has been taken in the interpretation of the results to exclude the possibility that the above described effect is responsible for the measured axial gas and tar profile.

\section{Results and discussion}

The axial evolution of the tar and gas composition is discussed in this section. The detailed tar results for the two different bed heights are presented in Tables 4 and 5 . For the discussion, the tar species are sorted into the five class system proposed by ECN [9]. The values that are presented for the gas composition are mean values over a time period of approximately $15 \mathrm{~min}$. The values presented for the tar composition are mean values from two samples.

\subsection{Axial evolution of the gas composition}

Figs. 2 and 3 show the axial gas profiles of the two investigated bed heights. A mass balance of the elements $\mathrm{C}, \mathrm{H}$ and $\mathrm{O}$ has been made based on the measured input flows of steam and biomass
Table 4

Detailed tar results for lower bed height $400-500 \mathrm{~mm}$.

\begin{tabular}{|c|c|c|c|c|c|c|}
\hline $\begin{array}{l}\text { Axial position }(\mathrm{mm}) \\
\text { Species }\end{array}$ & Class & $\begin{array}{l}200 \\
\mathrm{~g} / \mathrm{m}^{3}\end{array}$ & $P^{300}$ & 400 & 500 & 650 \\
\hline Phenol & 2 & - & - & 0.19 & 0.30 & 0.32 \\
\hline o-Kresol & 2 & - & 0.05 & 0.03 & 0.05 & 0.05 \\
\hline m-Cresol & 2 & - & - & 0.01 & 0.08 & 0.08 \\
\hline Toluene & 3 & - & 0.09 & 0.85 & 1.36 & 1.28 \\
\hline o-Xyl/Sty ${ }^{\mathrm{a}}$ & 3 & - & 0.03 & 0.18 & 0.32 & 0.37 \\
\hline Indene & 3 & - & 0.02 & 0.11 & 0.24 & 0.34 \\
\hline Naphthalene & 4 & 0.06 & 0.14 & 0.42 & 0.75 & 0.96 \\
\hline Biphenyl & 4 & 0.02 & 0.02 & 0.04 & 0.06 & 0.08 \\
\hline Fluorene & 4 & 0.04 & 0.04 & 0.04 & 0.06 & 0.08 \\
\hline Anthracene & 4 & 0.03 & 0.05 & 0.06 & 0.05 & 0.07 \\
\hline Fluoranthene & 5 & - & - & - & 0.03 & 0.03 \\
\hline Pyrene & 5 & - & - & - & 0.03 & 0.04 \\
\hline Sum $^{\mathrm{b}}$ & & 0.14 & 0.59 & 3.82 & 6.15 & 6.08 \\
\hline Unknowns & & - & - & 0.13 & 0.65 & 0.80 \\
\hline
\end{tabular}

STP = standard temperature and pressure.

a Sum of o-Xylol and Styrol.

b Including unknown components.

pellets, the ultimate analysis of the pellets and the wet gas composition of the product gas at the exit of the gasifier. The closure of the mass balance is acceptable, it can be found in Table 3 .

The $\mathrm{H}_{2} \mathrm{O}$ value is the most important of the gas values for two reasons:

1. It is required for the calculation of the wet gas composition.

2. can be used as an indicator to what extent the pellets have already degassed: the lower the steam content, the higher the content of gas originating from the pellets. In our experiments only around $20 \%$ of the injected steam takes part in reforming and shift reactions, the rest exits the gasifier unchanged. So a decrease in the $\mathrm{H}_{2} \mathrm{O}$ means mainly a source of dry gases and a slight consummation through reforming and shift reactions.

In the lower part of the bed the product gas consists mainly of $\mathrm{H}_{2} \mathrm{O}$ (concentration by volume $80 \%$ ). This can be monitored for both bed heights. A high $\mathrm{H}_{2} \mathrm{O}$ in the lower part of the bed can be expected, since the wood pellets have released only a fraction of their volatile content. A great portion of the fuel is still in solid state. With higher axial position, the volume concentration of $\mathrm{H}_{2} \mathrm{O}$ decreases and reaches a value of $40 \%$ to $50 \%$ in the freeboard. The reason is the release of volatiles and the formation of the dry main gas components inside the fluidized bed. A relatively stable gas composition is monitored in the freeboard. The main gas components $\mathrm{CH}_{4}$, $\mathrm{CO}, \mathrm{CO}_{2}$ and $\mathrm{H}_{2}$ are increasing continuously inside over the bed height and have a maximum at the end of the bed.

Both measurement series show a minimum in the volume concentration of $\mathrm{H}_{2} \mathrm{O}$. For the first measurement (Fig. 2) this minimum is detected around $500 \mathrm{~mm}$, but is only in the range of the measurement error. For the second measurement (Fig. 3) this point is monitored in the range from $700 \mathrm{~mm}$ to $900 \mathrm{~mm}$ and is very distinct. The location of the minimum therefore depends on the bed height and occurs in the transition zone of the fluidized bed and the beginning of the freeboard. A reason for this behavior could be up floating, partially degassed pellets. These pellets release their remaining volatiles on the bed surface, thus decreasing the volume concentration of steam. Furthermore, the remaining char reacts with steam in the heterogeneous water-gas reaction (1).

$\mathrm{C}+\mathrm{H}_{2} \mathrm{O} \leftrightarrow \mathrm{CO}+\mathrm{H}_{2} \quad \Delta H=+119 \mathrm{~kJ} / \mathrm{mol}$

The difficulty in withdrawing gas samples from inside a fluidized bed has been addressed in Section 2.5. The possible impact on the measured gas profile is discussed in the following. An important effect could be that bubble phase or dense phase is overrepresented 
Table 5

Detailed tar results for higher bed height $800-900 \mathrm{~mm}$

\begin{tabular}{|c|c|c|c|c|c|c|c|c|c|c|}
\hline $\begin{array}{l}\text { Axial position }(\mathrm{mm}) \\
\text { Species }\end{array}$ & Class & $\begin{array}{l}200 \\
\mathrm{~g} / \mathrm{m}^{3} \mathrm{STP}\end{array}$ & 300 & 400 & 500 & 600 & 700 & 900 & 1100 & 1200 \\
\hline Phenol & 2 & 0.04 & 0.06 & 0.05 & 0.03 & 0.02 & 0.08 & 0.81 & 1.22 & 1.22 \\
\hline o-Cresol & 2 & - & - & - & - & - & - & 0.07 & 0.11 & 0.15 \\
\hline $\mathrm{m}$-Cresol & 2 & - & - & - & - & - & 0.01 & 0.28 & 0.39 & 0.45 \\
\hline Toluene & 3 & - & 0.03 & 0.10 & 0.22 & 0.27 & 0.53 & 1.70 & 0.51 & 1.07 \\
\hline o-Xyl/Sty ${ }^{\mathrm{a}}$ & 3 & - & 0.02 & 0.07 & 0.05 & 0.06 & 0.10 & 0.46 & 0.49 & 0.52 \\
\hline Indene & 3 & - & 0.03 & 0.03 & 0.02 & 0.02 & 0.05 & 0.42 & 0.57 & 0.59 \\
\hline Naphthalene & 4 & 0.09 & 0.16 & 0.14 & 0.14 & 0.16 & 0.30 & 0.90 & 0.89 & 0.80 \\
\hline Biphenyl & 4 & 0.02 & 0.02 & 0.01 & 0.01 & 0.01 & 0.02 & 0.07 & 0.07 & 0.06 \\
\hline Fluorene & 4 & 0.04 & 0.04 & 0.04 & 0.03 & 0.04 & 0.03 & 0.09 & 0.11 & 0.11 \\
\hline Anthracene & 4 & 0.05 & 0.04 & 0.04 & 0.04 & 0.04 & 0.04 & 0.06 & 0.07 & 0.07 \\
\hline Fluoranthene & 5 & - & - & - & - & - & - & 0.04 & 0.05 & 0.05 \\
\hline Pyrene & 5 & - & - & - & - & - & 0.01 & 0.04 & 0.05 & 0.04 \\
\hline Sum $^{\mathrm{b}}$ & & 0.23 & 0.39 & 0.68 & 1.02 & 1.52 & 2.76 & 8.72 & 6.38 & 7.73 \\
\hline Unknowns & & - & - & 0.07 & 0.08 & 0.08 & 0.12 & 1.25 & 1.32 & 1.37 \\
\hline
\end{tabular}

STP = standard temperature and pressure

a Sum of o-Xylol and Styrol.

b Including unknown components.

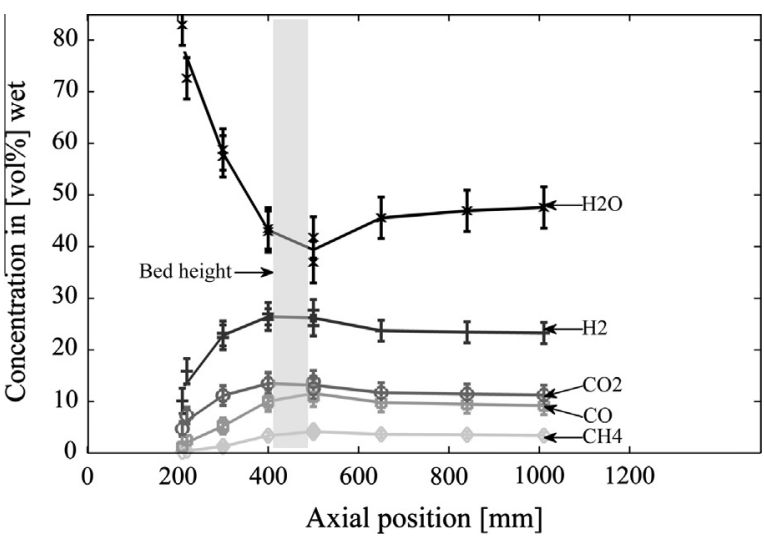

Fig. 2. Axial gas profile for bed height $400-500 \mathrm{~mm}$; calculated wet gas compositions.

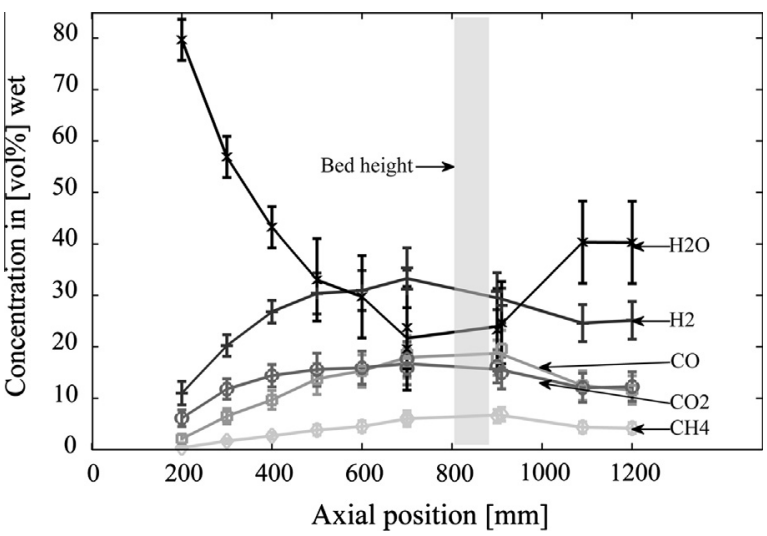

Fig. 3. Axial gas profile for bed height $800-900 \mathrm{~mm}$; calculated wet gas compositions.

in the measurements. As mentioned in Section 2.5, the bubbles contain initially only steam and if bubble phase and dense phase are not well mixed, a sharp drop in the steam content should be measurable in the freeboard where the bubbles break up if the bubble phase was overrepresented before. For the lower bed (Fig. 2) at the beginning of the freeboard no sharp drop in steam can be detected, the volume concentration of all gases does not change significantly from the axial position $400 \mathrm{~mm}$ to $1050 \mathrm{~mm}$. We assume that in this measurement both phases are equally represented. For the higher bed (Fig. 3) even an increase in the steam value from $900 \mathrm{~mm}$ to $1100 \mathrm{~mm}$ can be indicated. This indicates that either steam is consumed in this area as discussed above, or that the dense phase has been overrepresented.

\subsubsection{Summary of axial gas profile results}

One can indicate three zones in the fluidized bed gasifier: the fluidized bed where a major part of the volatiles are released, a transition zone between fluidized bed and freeboard where partially degassed particles release the rest of the volatiles, and the freeboard. This is independent of the absolute bed height and can be observed for the lower bed of $400-500 \mathrm{~mm}$ as well as for the higher bed of $800-900 \mathrm{~mm}$.

\subsection{Axial evolution of the tar composition}

The problem that bubble- or dense phase can be overrepresented in the withdrawn gas is not of such great importance in case of the tar measurement. As mentioned in Section 2.3, $100 \mathrm{ml}$ of dry gas are sampled since the steam condenses in the SPA sample. Hence the basis of the tar concentration $c_{t a r}$ is always the dry product gas and the unit is $\left[\mathrm{g} / \mathrm{m}_{d r y}^{3}\right]$. The total mass flow of tar $\dot{m}_{t a r}$ at each height then depends on the volume flow of the dry gases $\dot{V}_{d r y}$ with:

$\dot{m}_{\text {tar }}=c_{\text {tar }} \cdot \dot{V}_{\text {dry }}$.

According to the measured gas profiles, the volume flow of the dry gases increases continuously along the axis.

\subsubsection{Tar sum}

In Figs. 4 and 5 the profiles of the measured total tar sum are presented. For both measurement series the tar concentration increases from bottom to top of the gasifier. With the increasing release of the volatiles that was discussed in Section 3.1 the tar concentration also increases as expected. The highest tar concentrations are measured just above the bed in the splash zone for both cases. In case of the $400-500 \mathrm{~mm}$ bed the highest value is $6.1 \mathrm{~g} / \mathrm{m}^{3}$ (STP). The highest value in the $800-900 \mathrm{~mm}$ bed is $8.7 \mathrm{~g} / \mathrm{m}^{3}$. This difference must not be linked to the height of the bed. The lower bed produces less tar because it contained a higher amount of char that is beneficial in tar destruction (see [18]). Clearly recognizable for the lower bed (Fig. 4) is a sharp increase in the tar concentration at a height of $400 \mathrm{~mm}$. For the higher bed (Fig. 5) this sharp increase is found at $900 \mathrm{~mm}$. For both cases 


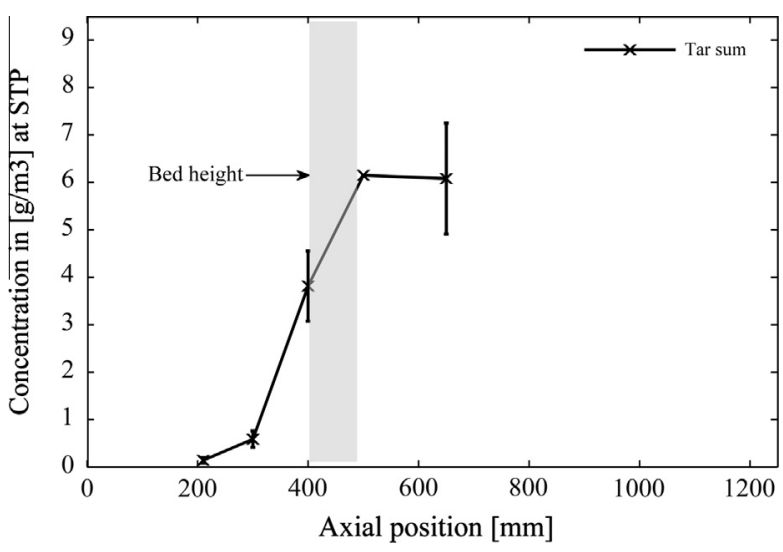

Fig. 4. Axial profile of tar sum for bed height of $400-500 \mathrm{~mm}$.

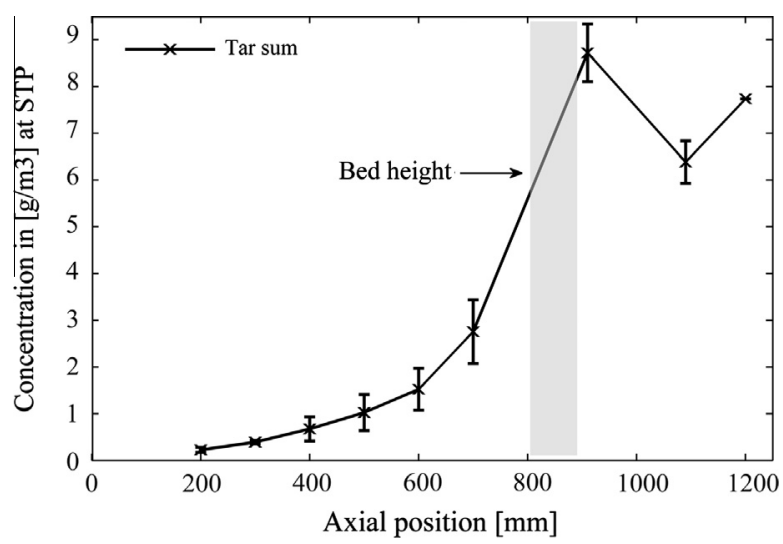

Fig. 5. Axial profile of tar sum for bed height of $800-900 \mathrm{~mm}$.

this increase coincides with the beginning of the freeboard. Here a major part of the tar concentration seems to be released.

As mentioned in Section 2.3, a high volume concentration of $\mathrm{H}_{2} \mathrm{O}$ in the gas leads to reduced tar adsorption on the SPA sample. Since the $\mathrm{H}_{2} \mathrm{O}$ changes significantly along the axis it has to be discussed whether this effect dominates the measurement. For the lower bed, the volume concentration of $\mathrm{H}_{2} \mathrm{O}$ changes from $58 \%$ to $46 \%$ from $300 \mathrm{~mm}$ to $650 \mathrm{~mm}$ while the tar concentration increases by a factor of 10 . For the higher bed, the volume concentration of $\mathrm{H}_{2} \mathrm{O}$ changes from $43 \%$ to $40 \%$ from $400 \mathrm{~mm}$ to $1100 \mathrm{~mm}$, the tar concentration also increases by a factor of 10 . It is highly unlikely that this tremendous increase in tar is only caused by a reduced adsorption behavior due to the relative small differences in the $\mathrm{H}_{2} \mathrm{O}$ concentration.

The evolution of the tar classes is presented in Figs. 6 and 7. As already mentioned, the unknown tar species are assigned to one of the tar classes according to their retention time. The class-specific results are discussed in the following.

\subsubsection{Class 2 components (heterocyclic)}

For the lower bed (Fig. 6) these tar species are not measurable at the bottom of the bed. A significant amount can be measured from $400 \mathrm{~mm}$ on.

For the higher bed (Fig. 7) more values are available leading to a better resolution of the profile. In the first $700 \mathrm{~mm}$ inside the fluidized bed only very low amounts of class 2 components are measurable. Also no increase of these components can be monitored inside the fluidized bed. It seems that the presence of the hot bed material leads to an efficient conversion of the oxygen contain-

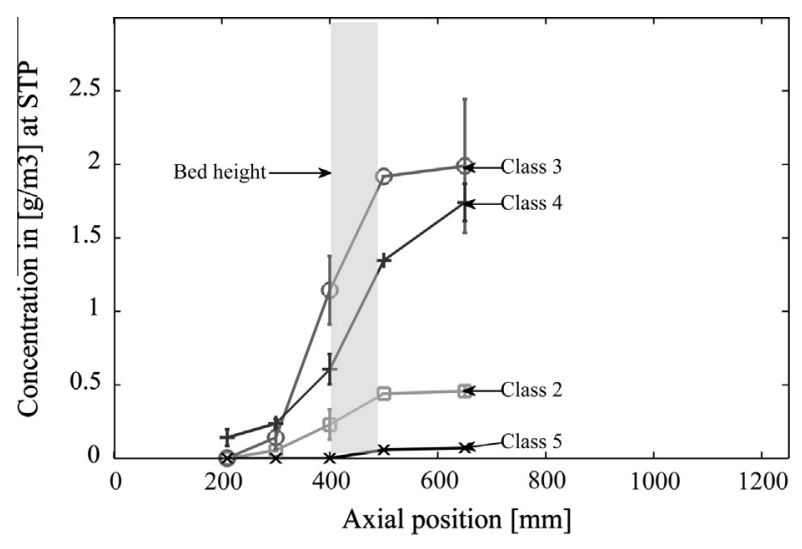

Fig. 6. Axial profile of tar classes for bed height of 400-500 mm.

ing class 2 tar species. A sharp increase can be observed at the beginning of the freeboard. The tar concentration increases further in the freeboard.

\subsubsection{Class 3 components (light aromatic)}

For the lower bed no class 3 species can be detected at the lowest measuring point. The value at $300 \mathrm{~mm}$ is significantly higher compared to class 2 tars and at $400 \mathrm{~mm}$ one can again observe the sharp increase. In the freeboard the value is rising further, even so the last value contains a larger uncertainty.

For the higher bed, class 3 components are measurable from a height of $300 \mathrm{~mm}$ and higher. These species increase continuously up to a height of $700 \mathrm{~mm}$. This differs greatly from the class 2 components which are not rising over the bed height. A possible explanation is the formation of class 3 species out of the class 2 species after they dissociate the hetero atoms, e.g. the formation of toluene out of cresol. The sharp increase is again observed at the beginning of the freeboard. The profile in the freeboard cannot be fully explained. First, one observes a sharp decrease from $900 \mathrm{~mm}$ to $1100 \mathrm{~mm}$, followed by an increase. This behavior of the class 3 species is caused by changes in the toluene concentration (see Table 5), the o-xylene/styrene and indene concentration do not show high fluctuations in the freeboard. A possible explanation is that toluene was lost from the SPA sample before elution. Since toluene has the lowest boiling point it is the tar compound that is mostly affected by temperature before elution.

\subsubsection{Class 4 components (light polyaromatic)}

For the lower bed, class 4 tars are the only class that can be measured also at the lowest location of $200 \mathrm{~mm}$. The value increases inside the bed and also shows an increase at the beginning of the freeboard. This increase is not as distinct as that observed for the class 3 components. The values increase further in the freeboard.

With the higher bed, class 4 components can also be detected at $200 \mathrm{~mm}$. They increase slightly inside the bed, but not as distinctly as the class 3 species. At the beginning of the freeboard they increase significantly, higher in the freeboard the concentration does not change significantly.

\subsubsection{Class 5 components (heavy polyaromatic)}

Class 5 components have the lowest concentration of all tar classes. For the lower bed, class 5 species are only measurable after $500 \mathrm{~mm}$. For the higher bed, they are also only detectable in the freeboard. The large polyaromatic tars are formed out of smaller ring systems, e.g. by a Diels-Alder mechanism or energy rich radicals at high temperature (see [19]). The presence of high amounts 


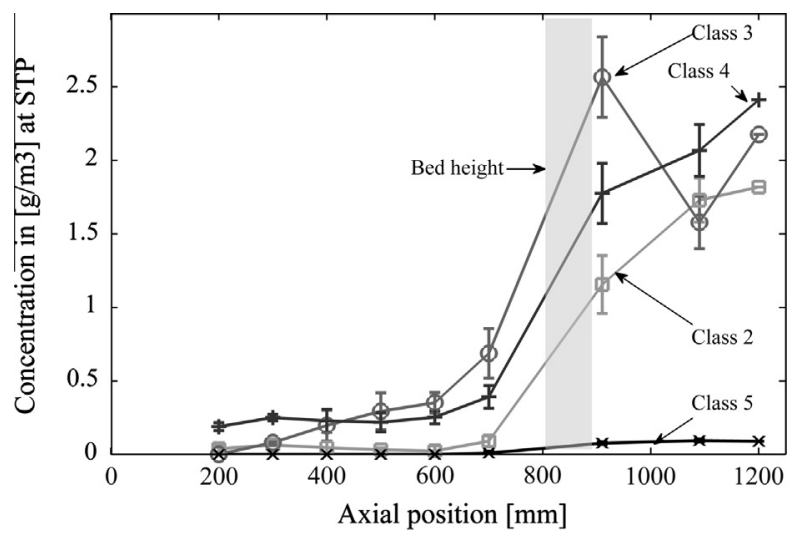

Fig. 7. Axial profile of tar classes for bed height of $800-900 \mathrm{~mm}$.

of steam in our experiments might be the reason that they cannot be formed.

\subsubsection{Summary of axial tar profile results}

Inside the bed, only a low tar concentration can be measured. Although a large amount of dry gases has been formed inside the bed, the emitted tar seems to be converted in the presence of the hot bed material. Especially the reactive class 2 species are hardly measurable inside the bed. At the beginning of the freeboard the tar concentration increases significantly, most likely emitted from partially degassed fuel particles floating on the top of the bed. Without the presence of the hot bed material the tar concentration stays mostly constant in the freeboard of our gasifier.

\subsection{Mixing of biomass and bed material}

The location of the tar release is linked to the location where the biomass particles are degassing. It is briefly discussed whether the biomass particles are mixed with the bed material or tend to float up to the bed surface where they react.

Ottmann [20] carried out investigations in cold gas bubbling fluidized beds and found three conditions that have to be fulfilled for proper mixing:

1. a high fluidization number,

2. small fuel particles,

3. and a high fuel density.

The fluidization number is significantly higher than required for minimum fluidization (see Table 1 ) hence the first condition is fulfilled. In comparison to wood chips, the typical fuel for biomass gasification, wood pellets can be regarded as small and also the second condition is satisfied. The fuel density is high for a fresh wood pellet (approximately $1100 \mathrm{~kg} / \mathrm{m}^{3}$ ), the bulk density of the fluidized bed is between $1050 \mathrm{~kg} / \mathrm{m}^{3}$ and $1500 \mathrm{~kg} / \mathrm{m}^{3}$ so this condition is fulfilled initially. Due to the release of the volatiles the density is reduced with prolonged residence time. An estimation of the residual char density is in the range of $200-400 \mathrm{~kg} / \mathrm{m}^{3}$. Hence the residual char is light enough to float on the surface. This is observed after shut down of the gasifier in form of a layer that is rich in residual char on top of the bed material. During degassing a biomass pellet gradually reduces its density and will float up at a certain threshold value before all volatiles are released. It is reported by Solimene et al. that degassing of a particle in a fluidized bed results in an additional lift force [21]. It is concluded from these considerations that partially degassed particles float on the bed surface and release the remaining volatiles. Since the particles stay in this zone until they are completely degassed, at this point a concentrated source of volatiles exists.

\section{Conclusions}

This study reports experimental results of allothermal steamblown bubbling fluidized bed gasification of biomass. The focus is to investigate the processes inside the fluidized bed by measuring axial gas and tar profiles.

In the gasifier used the tar that is released inside the bed can be efficiently converted in the presence of the hot bed material. This is concluded from the high volume concentration of dry gases in the upper part of the bed and the low tar concentration at the same point. The transition zone between bed and freeboard seems to play an important role in the release of tar compounds. Here the largest amount of tar is released through partially degassed particles that float on the bed and release the remaining part of the volatiles. For the lower bed approximately $80 \%$ of all tar is released in this zone, for the higher bed approximately $70 \%$ of the tar is released.

To produce a product gas in fluidized beds with a low raw tar concentration the up floating has to be kept to a minimum.

\section{Acknowledgment}

The support of the company Lantmannen (Sweden) is gratefully acknowledged for providing biomass feedstock.

\section{References}

[1] Haas R, Panzer C, Resch G, Ragwitz M, Reece G, Held A. A historical review of promotion strategies for electricity from renewable energy sources in eu countries. Renew Sust Energy Rev 2011;15(2):1003-34.

[2] Wang Lijun, Curtis Weller L, David Jones D, Milford Hanna A. Contemporary issues in thermal gasification of biomass and its application to electricity and fuel production. Biomass Bioenergy 2008;32(7):573-81.

[3] Chang J, Fu Y, Luo Z. Experimental study for dimethyl ether production from biomass gasification and simulation on dimethyl ether production: biorefinery. Biomass Bioenergy 2012;39(0):67-72.

[4] Corella J, Toledo JM, Molina G. A review on dual fluidized-bed biomass gasifiers. Ind Eng Chem Res 2007;46(21):6831-9.

[5] Murakami T, Xu G, Suda T, Matsuzawa Y, Tani H, Fujimori T. Some process fundamentals of biomass gasification in dual fluidized bed. Fuel 2007;86(12):244-55.

[6] Milne T, Evans R. Biomass gasifier "tars": their nature, formation, and conversion; 1998.

[7] Rabou LPLM, Zwart RWR, Vreugdenhil BJ, Bos L. Tar in biomass producer gas the energy research centre of the Netherlands (ECN) experience: an enduring challenge. Energy Fuels 2009;23(23):6189-98.

[8] Devi L, Ptasinski KJ, Janssen F. A review of the primary measures for tar elimination in biomass gasification processes. Biomass Bioenergy 2003;24(2):125-40.

[9] Kiel J, Primary measures to reduce tar formation in fluidised-bed biomass gasifiers: final Report SDE Project P1999-012. ECN-C; Netherlands Energy Research Foundation; 2004.

[10] Brage C, Yu Q, Chen G, Sjöström K. Use of amino phase adsorbent for biomass tar sampling and separation. Fuel 1997;76(2):137-42.

[11] van Paasen SV. Tar formation in a fluidised bed gasifier: Impact of fuel properties and operating conditions; 2004.

[12] Ross D, Noda R, Horio M, Kosminski A, Ashman P, Mullinger P. Axial gas profiles in a bubbling fluidised bed biomass gasifier. Fuel 2007;86(1011):1417-29.

[13] Mayerhofer M, Mitsakis P, Meng X, Jong Wd, Spliethoff H, Gaderer M. Influence of pressure temperature and steam on tar and gas in allothermal fluidized bed gasification. Fuel 2012;99(0):204-9.

[14] Basu P. Combustion and gasification in fluidized beds. Boca Raton and FL: Taylor \& Francis; 2006. ISBN 0-8493-3396-2.

[15] Dufour A, Girods P, Masson E, Normand S, Rogaume Y, Zoulalian A. Comparison of two methods of measuring wood pyrolysis tar. J Chromatogrophy A 2007;1164(1-2):240-7.

[16] Tepper H. Zur vergasung von rest- und abfallholz in wirbelschichtreaktoren für dezentrale energieversorgungsanlagen. Ph.D. thesis; Otto-von-GuerickeUniversität Magdeburg; Magdeburg; 2005.

[17] Grace J, Bi H, Zhang Y. Pitfalls in gas sampling from fluidized beds. Chem Eng Sci 2009;64(10):2522-4. http://dx.doi.org/10.1016/j.ces.2009.02.012. 
[18] Abu El-Rub ZYK. Biomass char as an in-situ catalyst for tar removal in gasification systems. Enschede: University of Twente [Host]; 2008. ISBN 978 90-365-2637-1.

[19] Unger C, Ising M. Mechanismen und bedeutung der teerbildung und teerbeseitigung bei der thermochemischen umwandlung feste kohlenstoffträger. In: Adlhoch $\mathrm{W}$, editor. Beiträge zur DGMKFachbereichstagung Energetische Nutzung von Biomassen. Hamburg: DGMK; 2002. p. 131-42. ISBN 3-931850-91-9.
[20] Ottmann M. Verbrennung biogener brennstoffe in stationären wirbelschichtfeuerungen. Ph.D. thesis. München: Technische Universität München; 2007.

[21] Solimene R, Marzocchella A, Salatino P. Hydrodynamic interaction between a coarse gas-emitting particle and a gas fluidized bed of finer solids. Powder Technol 2003;133(1-3):79-90. 